\title{
Factors associated with physical activity among COPD patients with mild or moderate airflow obstruction
}

\author{
Amanda R. van Buul${ }^{1}$, Marise J. Kasteleyn ${ }^{1,2}$, Vitalii Poberezhets ${ }^{3}$, Tobias N. Bonten ${ }^{1,2}$, Renée de Mutsert ${ }^{4}$, \\ Pieter S. Hiemstra1, Saskia le Cessie ${ }^{4,5}$, Frits R. Rosendaal ${ }^{4,6}$, Niels H. Chavannes ${ }^{2}$, Christian Taube ${ }^{1,7}$ \\ ${ }^{1}$ Department of Pulmonology, Leiden University Medical Center, Leiden, The Netherlands; ${ }^{2}$ Department of Public Health \\ and Primary Care, Leiden University Medical Center, Leiden, The Netherlands; ${ }^{3}$ Department of Propedeutics of Internal \\ Medicine, National Pirogov Memorial Medical University, Vinnytsya, Ukraine; ${ }^{4}$ Department of Clinical Epidemiology, \\ Leiden University Medical Center, Leiden, The Netherlands; ${ }^{5}$ Department of Medical Statistics and Bioinformatics, \\ Leiden University Medical Center, Leiden, The Netherlands; ${ }^{6}$ Department of Thrombosis and Hemostasis, Leiden \\ University Medical Center, Leiden, The Netherlands; ${ }^{7}$ Department of Pulmonary Medicine, University Hospital Essen, \\ Ruhrlandklinik, University Duisburg-Essen, Essen, Germany
}

\begin{abstract}
Physical inactivity is already present among patients with chronic obstructive pulmonary disease (COPD) of mild or moder-
\end{abstract}

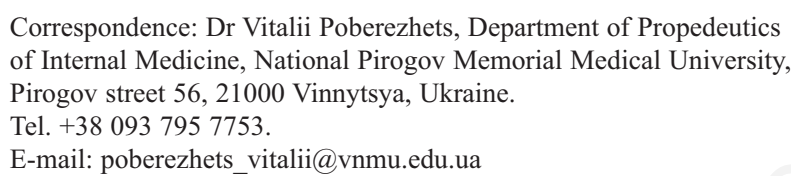

Key words: Physical activity; chronic obstructive pulmonary disease; pulmonology; general practice.

Contributions: AB, MK, TB, RM, PH, SC, FR, NC, CT, conception or design of the work/data acquisition/data analysis/interpretation of data; VP, data interpretation; $\mathrm{AB}, \mathrm{MK}, \mathrm{VP}, \mathrm{TB}, \mathrm{RM}$ manuscript drafting; PH, SC, FR, NC, CT manuscript revision. All the authors have read and approved the final version of the manuscript and greed to be accountable for all aspects of the work.

Ethics approval and consent to participate: the Medical Ethical Committee of the Leiden University Medical Center approved the study design; all participants gave their written informed consent.

Conflict of interest: The authors declare that they have no competing interests, and all authors confirm accuracy.

Acknowledgements: We thank Ingeborg de Jonge (Dept of Clinical Epidemiology, LUMC, Leiden, The Netherlands) for data management of the NEO study.

Received for publication: 29 April 2021.

Accepted for publication: 29 June 2021.

${ }^{\circ}$ Copyright: the Author(s), 2021

Licensee PAGEPress, Italy

Monaldi Archives for Chest Disease 2022; 92:1891

doi: 10.4081/monaldi.2021.1891

This article is distributed under the terms of the Creative Commons Attribution Noncommercial License (by-nc 4.0) which permits any noncommercial use, distribution, and reproduction in any medium, provided the original author(s) and source are credited. ate airflow obstruction. Most previous studies that reported on determinants of physical activity in COPD included patients with severe COPD. Therefore, this study aimed to explore which patient characteristics were related to physical activity in COPD patients with mild or moderate airflow obstruction. Cross-sectional analyses were performed on patients selected from the population-based Netherlands Epidemiology of Obesity study. Patients were included if they had a physician-diagnosed COPD GOLD 02 or had newly diagnosed COPD GOLD 1-2. Physical activity was evaluated using the Short Questionnaire to Assess HealthEnhancing Physical Activity (SQUASH) questionnaire and reported in hours per week of metabolic equivalents (MET-h/week). Associations between sociodemographic, lifestyle, clinical and functional characteristics were examined using regression analysis. 323 patients were included in research (77 with physiciandiagnosed and 246 with newly diagnosed COPD). We found that physical activity was positively associated with pulmonary function: FEV1 (regression coefficient 0.40 (95\% CI 0.09,0.71)) and FVC (regression coefficient 0.34 (95\% CI 0.06,0.61)). Physical activity was associated with anxiety (regression coefficient $=0.9$ $(95 \%$ CI $0.3,1.6))$ only for physician-diagnosed patients. Lung function and anxiety level determine the level of physical activity among COPD patients with mild or moderate airflow obstruction. Thus, adjusting physical activity plans accordingly could help to increase physical activity level of the patients.

\section{Introduction}

Physical inactivity is a common worldwide problem and is especially observed in patients with chronic diseases such as chronic obstructive pulmonary disease (COPD) [1]. Only $26 \%$ to $30 \%$ of patients with COPD were reported to fulfil the World Health Organisation physical activity recommendations compared to $54 \%$ among apparently healthy adults [1]. Inactivity in COPD is associated with more hospitalizations and mortality [2].The European Respiratory Society statement on physical activity in COPD recommends sufficient physical activity in COPD [3]. However, it is incompletely understood why patients with COPD are inactive [4,5]. Defining patient characteristics that are associated with physical inactivity is important for the development of targeted interventions, also for COPD patients 
with mild or moderate airflow obstruction. The decline in physical activity already starts in mild disease stages [5-8], even before the physician diagnosis of COPD is made. Unfortunately, half of the patients already have COPD GOLD 2 when the diagnosis is confirmed by spirometry [9].

Multiple characteristics have been reported to be related to physical activity in COPD [3], but the role of most characteristics is unclear and inconsistent findings have been reported [10]. In addition, in most previous studies regarding physical activity, only half of the COPD patients had mild or moderate airflow obstruction [5,8,11-14], or had a mean forced expiratory volume in one second (FEV1) lower than 50\% [15-21]. Studies that included only COPD patients with mild or moderate airflow obstruction are sparse $[6,7]$. Therefore, the characteristics that are associated with physical activity in this patient group are unclear and needs to be further studied since, in our view, in this patient population there appears to be most room for improvement. In this study, patients with COPD Global Initiative for Chronic Obstructive Lung Diseases (GOLD) 0, 1 and 2 were investigated. Patients who are not diagnosed with COPD yet, but who have an obstructive pulmonary function, with respiratory symptoms and/or smoking history, were included as well to cover the group that will be diagnosed when the pulmonary function has further declined.

The present study aimed to explore physical activity and patient characteristics that were associated with physical activity in patients with physician-diagnosed COPD GOLD 0, 1 and 2 and newly diagnosed COPD GOLD 1 and 2.

\section{Materials and Methods}

\section{Study design}

Cross-sectional analyses of baseline data from the Netherlands Epidemiology of Obesity (NEO) study are presented. The NEO study is a population-based prospective cohort study, with an oversampling of individuals with a body mass index (BMI) of $27 \mathrm{~kg} / \mathrm{m}^{2}$ or higher. From 2008 to 2012, 6,671 participants were included in the NEO study. The study design and population are described in detail elsewhere [22]. Briefly, men and women, aged between 45 and 65 years with a self-reported BMI of $27 \mathrm{~kg} / \mathrm{m}^{2}$ or higher, living in the greater area of Leiden, the Netherlands, were invited to participate. In addition, all inhabitants aged between 45 and 65 years in one municipality (Leiderdorp, the Netherlands) with different BMI were invited (irrespective of their BMI), allowing for a reference distribution of BMI. Of the 8,229 inhabitants of Leiderdorp who were sent an invitation to participate, 1,671 participated in the NEO study. As a result, 5,217 participants had a BMI of $27 \mathrm{~kg} / \mathrm{m} 2$ or higher. All participant were Dutch residents who lived in the moderate marine climate typical for the Netherlands.

Participants were invited to a baseline visit at the NEO study centre. Prior to this study visit, patients fulfilled questionnaires about data on demography, lifestyle (including a physical activity questionnaire), and medical history (including comorbidities and an investigator designed questionnaire about respiratory symptoms that included dyspnoea, wheezing, cough, sputum production or other respiratory symptoms) [22]. During the study visit, participants underwent an extensive physical examination with a prebronchodilator pulmonary function. International Classification of Primary Care (ICPC) codes and medication prescription before the study visit were obtained through the electronic medical record registry of the general practitioners.

\section{Study population}

\section{Inclusion criteria}

We included men and women, aged between 45 and 65 years. For those living in the greater area of Leiden, the Netherlands, participants required to have anBMI $\geq 27 \mathrm{~kg} / \mathrm{m}^{2}$. There were no requirements for BMI for invited inhabitants of Leiderdorp, the Netherlands. We included patients with "physican-diagnosed COPD" and "newly diagnosed COPD".Participants who have been already diagnosed with COPD by their physician (with an ICPC code for COPD (R95) according to GP medical record), were labelled "physician-diagnosed COPD". The diagnosis of COPD among this group was made based on COPD standards of the Dutch College of General Practitioners (in Dutch: Nederlands Huisartsengenootschap - NHG), which includes spirometry assessment [23]. Furthermore, participants who were not physican diagnosed with COPD, but likely to have COPD based on their characteristics that were found during the study visit, were included in the group labelled "newly diagnosed COPD": patients without an ICPC code for COPD, but who have an obstructive pulmonary function $\left(\mathrm{FEV}_{1}\right.$ /forced vital capacity $\left.(\mathrm{FVC})<0.7\right)$ according to the spirometry, that was performed during the study visit, plus respiratory symptoms and/or a smoking history of at least 20 pack-years [24]

\section{Exclusion criteria}

Participants were excluded if the $\mathrm{FEV}_{1}$ was lower than $50 \%$ since the focus of this study was on COPD patients with mild or moderate airflow obstruction; if they had characteristics that were more suggestive for asthma. A diagnosis of asthma was an exclusion criterion. Never smokers were excluded since COPD is mostly caused by cigarette smoking in Western countries. Moreover, patients with a FeNO concentration in exhaled breath of $\geq 25$ parts per billion were excluded since an increased FeNO is associated with eosinophilic inflammation that is more common in asthma than in COPD. Participants with missing data on the key variables were excluded as well.

\section{COPD severity}

COPD severity was solely based on airflow obstruction. Patients with physician-diagnosed COPD and a $\mathrm{FEV}_{1} / \mathrm{FVC}<0.7$ and an $\mathrm{FEV}_{1} \geq 80 \%$ predicted were classified as physician-diagnosed GOLD 1; those with a $\mathrm{FEV}_{1} / \mathrm{FVC}<0.7$ and a $\mathrm{FEV}_{1} 50-80 \%$ predicted as physician-diagnosed GOLD 2. Patients with a ICPC code for COPD (thus a physician-diagnosed COPD), but no airway obstruction during baseline visit $\left(\mathrm{FEV}_{1} / \mathrm{FVC}>0.7\right)$, patients were classified as COPD GOLD 0. All patients with newly diagnosed COPD had an airflow obstruction $\left(\mathrm{FEV}_{1} / \mathrm{FVC}<0.7\right)$ according to the inclusion criteria. Newly diagnosed patients with a $\mathrm{FEV}_{1} \geq 80 \%$ predicted were classified as newly diagnosed GOLD 1; those with a $\mathrm{FEV}_{1} 50-80 \%$ predicted as newly diagnosed GOLD 2 .

\section{Data collection}

\section{Physical activity}

Participants in the NEO study reported their usual weekly physical activity during the preceding four weeks with the validated Short Questionnaire to Assess Health-enhancing physical activity (SQUASH) [25]. Participants reported the frequency and duration of their physical activity in leisure time, which was expressed in hours per week of metabolic equivalents (MET-h/week). 


\section{Patient characteristics}

We selected characteristics that can be associated with physical activity (reported in previous studies and summarized in a previous review) [10.] We collected sociodemographic and lifestyle characteristics (age, sex, pack-years, alcohol consumption, ethnicity, education level, working status and smoking status), clinical and functional characteristics (respiratory symptoms, anxiety, depression, $\mathrm{BMI}, \mathrm{FEV}_{1}$ and $\mathrm{FVC}$ ). Ethnicity was grouped into white and other; education level into high and low; working status into working and not working, smoking status into current and former. Respiratory symptoms included dyspnoea, wheezing, cough, sputum production or other respiratory symptoms that could be reported on the questionnaire. Participants reported symptoms or no symptoms. They reported on the questionnaire whether they experienced an increase in symptoms in the morning or no increase. Anxiety and depression were examined with the Beck Anxiety Inventory (BAI) [26] and the Inventory of Depressive Symptomatology (IDS) questionnaire, respectively [27]. Lung function was assessed by spirometry (Jaeger Masterscreen PFT; Viasys Healthcare, Hoechberg, Germany), which was performed according to the standards of the European Respiratory Society [28]. Pre-bronchodilator $\mathrm{FEV}_{1}$ and $\mathrm{FVC}$ were reported in absolute values and as percentage predicted normal based on sex, age and height.

\section{Statistical analysis}

Descriptive data of baseline characteristics were reported as percentages, mean and standard deviation (SD) when normally distributed, or as median and interquartile range (IQR) when not normally distributed.

Differences in baseline characteristics between participants were tested, using linear regression analyses. For nonnormally distributed variables and dichotomous variables, linear regression analyses with robust standard errors were used.

Univariate regression analysis was used to evaluate the association between characteristics and physical activity. Since age and sex are associated with physical activity in healthy older people, as well in COPD patients [10,29], analyses were adjusted for age and sex. Given the non-normal distribution of physical activity, regression coefficients and robust standard errors were used to calculate $95 \%$ confidence intervals.

We did not perform the comparison of COPD patients with and without cardiovascular or diabetes comorbidities, as it is already a confirmed fact that multiple other chronic diseases reduce physical activity [30]. Thereby, a sensitivity analysis was performed in which patients with comorbid cardiovascular disease or diabetes were excluded to evaluate other factors possibly related to physical inactivity. Moreover, patients with physician-diagnosed and patients with newly diagnosed COPD also might differ in physical activity. That is why another sensitivity analysis was performed that analyzed the association between characteristics and physical activity in physician-diagnosed and newly diagnosed COPD patients separately.

To investigate whether the association between determinants and physical activity was similar across the physician-diagnosed group and the newly diagnosed group, the interactions between each determinant and the group indicator (ICPC R95 present or not) were tested by fitting multiple linear regression models on both groups together. Also, the covariates age and sex were included. Since age and sex are associated with physical activity in healthy older people, as well as in COPD patients [10,29]. When the interaction was not statistically significant ( $p$-value for heterogeneity $>0.10$ ), a pooled estimate of the association between the determinant and physical activity was obtained. Given the non-normal distribution of physical activity, regression coefficients and robust standard errors were used to calculate $95 \%$ confidence intervals.

All results were weighted to represent a general population with a normal BMI distribution [31]. This was done by weighting the participants towards the BMI distribution of participants from the Leiderdorp municipality, whose BMI distribution was similar to the BMI distribution of the general Dutch population. Consequently, the results apply to a population-based study without oversampling of participants with a BMI $\geq 27 \mathrm{~kg} / \mathrm{m}^{2}$. Statistical analysis was performed using Stata Statistical Software version 14.1. (StataCorp, College Station, TX, USA).

\section{Results}

From the 6,671 participants in the NEO database, 323 participants $(4.8 \%$ of the total cohort) fulfilled the study criteria (Figure 1). Seventy-seven (77) patients had physician-diagnosed COPD and 246 patients had newly diagnosed COPD. Patients reported a median (IQR) of $31(15 ; 46)$ MET-h/week in physical activity. Table 1 and Table 2 show the general and pharmacological characteristics of all COPD patients included in the study and a group with the exclusion of patients with cardiovascular disease or diabetes $(\mathrm{n}=259)$.

Table 3 shows the associated characteristics of physical activity. After adjustment for age and sex, none of the sociodemographic and lifestyle characteristics were associated with physical activity. In the cluster clinical and functional characteristics, there was a positive association with $\mathrm{FEV}_{1}$ and $\mathrm{FVC}$. The regression coefficients were $0.40(95 \%$ CI $0.09,0.71)$ and 0.34 (95\% CI $0.06,0.61)$. This indicates an increase of $0.40 \mathrm{MET}$-h/week per percent $\mathrm{FEV}_{1}$ and an increase of $0.34 \mathrm{MET}-\mathrm{h} /$ week per percent FVC.

Table 4 shows characteristics of physical activity in the COPD population with the exclusion of patients with cardiovascular disease or diabetes. There were no other associations found. Table 5 shows baseline characteristics of physician-diagnosed and newly diagnosed patients separately. The majority $(55.4 \%)$ of participants met the criteria for newly diagnosed COPD GOLD 1. Table 6 show the associated characteristics of physical activity in physician-diagnosed and newly diagnosed patients. The characteristics of education, BMI, anxiety, depression, FEV1, and FVC showed a statistically significant heterogeneity $(\mathrm{p}<0.1)$ across physician-diagnosed and newly diagnosed patients. Therefore, these characteristics were not included in the overall estimation. Education, BMI and depression were not associated with physical activity in physician-diagnosed, neither in newly diagnosed patients. The association between anxiety and physical activity was positive and statistically significant (regression coefficient 0.9 MET-h/week; 95\% CI 0.3 , 1.6) only for physician-diagnosed patients. The regression coefficient of $0.9(95 \%$ CI $0.3,1.6)$ represents an increase in physical activity of 0.9 MET-h/week per point increase on the BAI. Statically significant positive associations between both $\mathrm{FEV}_{1}$ and FVC and physical activity were found only in newly diagnosed patients, but not in physician-diagnosed patients. The regression coefficients were 0.4 (95\% CI 0.1,0.7) and 0.34 (95\% CI 0.1, 0.6), respectively. This indicates an increase of $0.4 \mathrm{MET}-\mathrm{h} /$ week per percent $\mathrm{FEV}_{1}$ and an increase of $0.3 \mathrm{MET}$-h/week per percent FVC.

The determinants of working status, smoking status, alcohol 
intake, worsening of symptoms in the morning, and respiratory symptoms showed no significant heterogeneity and were included in the overall estimation. Pooled estimates showed no significant associations between the determinants and physical activity.

\section{Discussion}

The aim of the present study was to explore associated characteristics of physical activity in patients with COPD with mild or moderate airflow obstruction in a general population. Patients with physician-diagnosed and newly diagnosed COPD were included, while other studies only included patients with physician-diagnosed COPD and thereby missed undiagnosed patients. Physical activity was positively associated with pulmonary function. Furthermore, a sensitivity analysis showed that physical activity was associated with anxiety only for physician-diagnosed patients.
We found no association of physical activity with education level, working status, smoking status, alcohol intake, BMI, depression, respiratory symptoms or morning symptoms.

In the present study, patients reported higher physical activity levels as compared with a previous study that included patients with COPD with mild or moderate airflow obstruction, using accelerometry to evaluate physical activity [6]. Previous studies in this field did not make a distinction in physical activity between different COPD grades.

In the current study, pulmonary function was associated with physical activity. The showed association is in line with some $[11,16,17,32,33]$, but not all previous studies in patients with COPD $[15,18]$. Per decrease of percent $\mathrm{FEV}_{1}$, patients spent 0.4 MET-h/week less time in leisure-time physical activity. The exact clinical relevance of $0.4 \mathrm{MET}-\mathrm{h} /$ week is unknown $0.4 \mathrm{MET}$ $\mathrm{h} /$ week less time in leisure-time physical activity is might be a relevant number of MET-h/week in COPD, since the effect of intensive exercise training in COPD is only five minutes more walking

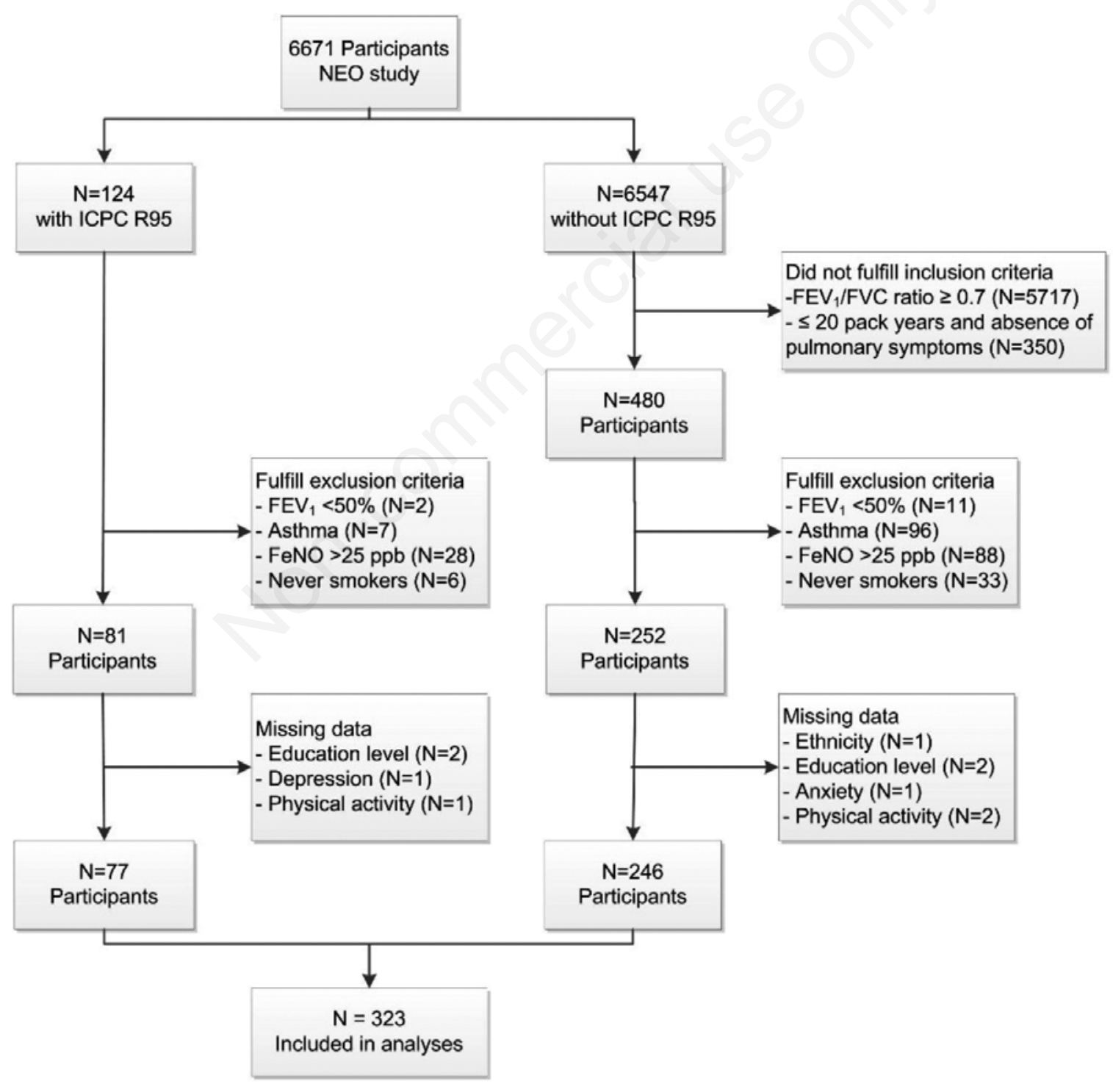

Figure 1. Flow chart of study design. COPD, chronic obstructive pulmonary disease; $\mathrm{Fe}_{\mathrm{NO}}$, fractional exhaled nitric oxide; $\mathrm{FEV}_{1}$, Forced expiratory volume in one second; FVC, forced vital capacity; NEO, Netherlands Epidemiology of Obesity. 
Table 1. General characteristics of all COPD patients and patients without comorbid cardiovascular disease or diabetes.

\begin{tabular}{|c|c|c|}
\hline Sociodemographic and lifestyle characteristics & $\begin{array}{l}\text { Baseline group } \\
\text { of COPD patients } \\
(n=323)\end{array}$ & $\begin{array}{l}\text { COPD patients } \\
\text { without cardiovascular } \\
\text { disease or diabetes } \\
(\mathrm{n}=259)\end{array}$ \\
\hline Age (years, median [IQR]) & $60[54-63]$ & $60[54-63]$ \\
\hline Sex (\% women $)$ & 44 & 47 \\
\hline Ethnicity (\% white) & 98 & 98 \\
\hline Education level (\% high) & 34 & 33 \\
\hline Working status (\% working) & 53 & 54 \\
\hline Smoking (\% current) & 50 & 53 \\
\hline Pack-years (mean, (SD)) & $29(18)$ & $28(17)$ \\
\hline Alcohol intake (g/d, median [IQR]) & $21[6-34]$ & $21[6-34]$ \\
\hline \multicolumn{3}{|l|}{ Clinical and functional characteristics } \\
\hline Physical activity in leisure time ( MET-h/week, median [IQR]) & $31[15 ; 46]$ & $31[15 ; 44]$ \\
\hline Pulmonary symptoms (\% yes) & 58 & 58 \\
\hline Worsening of symptoms in the morning (\% yes) & 16 & 16 \\
\hline BAI (median [IQR]) & $3[1-6]$ & $3[1-6]$ \\
\hline IDS (median [IQR]) & $8[5-14]$ & $7[5-14]$ \\
\hline BMI $\left(\mathrm{kg} / \mathrm{m}^{2}\right.$, mean $\left.( \pm \mathrm{SD})\right)$ & $27(5)$ & $26(4)$ \\
\hline FEV1 (\% predicted, mean $( \pm \mathrm{SD}))$ & $88(16)$ & $88(16)$ \\
\hline FVC (\% predicted, mean $( \pm$ SD $))$ & $111(16)$ & $111(17)$ \\
\hline FeNO (ppb, (median [IQR]) & 13 [9-17] & $13[9-16]$ \\
\hline \multicolumn{3}{|l|}{ COPD stage } \\
\hline Physician-diagnosed GOLD 0 (\%) & 5.6 & 5.5 \\
\hline Physician-diagnosed GOLD I (\%) & 7.3 & 7.3 \\
\hline Newly diagnosed GOLD I (\%) & 55.4 & 55.7 \\
\hline Physician-diagnosed GOLD II (\%) & 6.7 & 6.6 \\
\hline Newly diagnosed GOLD II (\%) & 25.0 & 24.9 \\
\hline
\end{tabular}

BAI, Beck anxiety inventory; BMI, body mass index; COPD, chronic obstructive pulmonary disease; Fe $e_{N o}$, fractional exhaled nitric oxide; FEV $\mathrm{F}_{1}$, forced expiratory volume in 1 second; FVC, forced vital capacity; GOLD, global initiative for chronic obstructive lung disease; ICPC, international classification of primary care; ICS, inhaled corticosteroids; IDS, inventory of depressive symptomatology; IQR, interquartile range; LABA, long-

Table 2. Pharmacological characteristics of baseline group of COPD patients and patients without comorbid cardiovascular disease or diabetes.

\begin{tabular}{|c|c|c|}
\hline & $\begin{array}{l}\text { Baseline group } \\
\text { of COPD patients } \\
(\mathrm{n}=323) \\
(\mathrm{n}=259)\end{array}$ & $\begin{array}{c}\text { COPD patients } \\
\text { without cardiovascular } \\
\text { disease or diabetes }\end{array}$ \\
\hline Any pulmonary (\%) & 19.8 & 20.1 \\
\hline $\begin{array}{c}\text { Short acting (\%) } \\
\text { SABA (\%) } \\
\text { SAMA (\%) } \\
\end{array}$ & $\begin{array}{l}5.2 \\
4.9 \\
0.7 \\
\end{array}$ & $\begin{array}{l}5.3 \\
5.3 \\
0.2 \\
\end{array}$ \\
\hline $\begin{array}{l}\text { Long acting (\%) } \\
\text { ICS monotherapy (\%) } \\
\text { LABA monotherapy (\%) } \\
\text { LAMA monotherapy (\%) } \\
\text { ICS+LABA (\%) } \\
\text { LABA+LAMA (\%) } \\
\text { ICS+LABA+LAMA(\%) } \\
\text { ICS (\%) } \\
\text { LABA (\%) } \\
\text { LAMA (\%) }\end{array}$ & $\begin{array}{l}15.7 \\
3.5 \\
0.6 \\
2.1 \\
5.3 \\
0.2 \\
4.0 \\
12.9 \\
10.0 \\
6.4\end{array}$ & $\begin{array}{l}16.4 \\
4.1 \\
0.4 \\
2.2 \\
5.4 \\
0.2 \\
4.0 \\
13.7 \\
10.0 \\
6.6\end{array}$ \\
\hline
\end{tabular}

BAI, Beck anxiety inventory; BMI, body mass index; COPD, chronic obstructive pulmonary disease; Fe $e_{N o}$, fractional exhaled nitric oxide; FEV , forced expiratory volume in 1 second; FVC, forced vital capacity; GOLD, global initiative for chronic obstructive lung disease; ICPC, international classification of primary care; ICS, inhaled corticosteroids; IDS, inventory of depressive symptomatology; IQR, interquartile range; LABA, longacting beta2 agonist; LAMA, long-acting muscarinic antagonist; MET, metabolic equivalent task; SABA, short-acting beta2 agonist; SAMA, short-acting muscarinic antagonist; SD, standard deviation. 
a day (which is equivalent to $1.75 \mathrm{MET}-\mathrm{h} /$ week) [34]. Patients with mild COPD have objectively measured greater ventilatory inefficiency than controls $[35,36]$, which might explain the lower physical activity. This is supported by another study in newly diagnosed COPD patients, showing that a lower diffusion capacity was associated with lower physical activity [6]. This association between low pulmonary function and physical inactivity resulted in disabled inactive patients with COPD.

A sensitivity analysis in the current study showed that physical activity was associated with anxiety only for physician-diagnosed patients. There could be a difference in perception of dyspnoea during physical activity between diagnosed and newly diagnosed patients: patients who are diagnosed with COPD might think "I am dyspnoeic during physical activity, that indicates that my COPD is getting worse, I have to practice more" and they become anxious; whereas patients without the diagnosis COPD might think "I am dyspnoeic during physical activity, that is a normal response of my body." Such subjective perception of dyspnea leads to the appearance of physical inactivity even among COPD patients without physical disability.

Table 3. Associated characteristics of physical activity in patients with COPD.

\begin{tabular}{|c|c|c|c|c|}
\hline \multirow[t]{2}{*}{ Characteristics } & \multicolumn{2}{|c|}{$\begin{array}{l}\text { Unadjusted leisure time physical activity } \\
\text { (MET-h/week) }\end{array}$} & \multicolumn{2}{|c|}{$\begin{array}{l}\text { Adjusted* leisure time physical activity } \\
\text { (MET-h/week) }\end{array}$} \\
\hline & Regression coefficient & $95 \% \mathrm{CI}$ & Regression coefficient & $95 \% \mathrm{CI}$ \\
\hline \multicolumn{5}{|l|}{ Sociodemographic and lifestyle characteristics } \\
\hline Education level (ref low) & -5.70 & $-14.9 ; 3.49$ & -7.13 & $-16.8 ; 2.51$ \\
\hline Working status (ref not working) & -9.11 & $-19.5 ; 1.26$ & -6.93 & $-21.1 ; 7.27$ \\
\hline Smoking status (ref former) & -2.81 & $-13.4 ; 7.72$ & -2.19 & $-12.7 ; 8.36$ \\
\hline Alcohol intake $(\mathrm{g} / \mathrm{d})$ & 0.20 & $-0.20 ; 0.60$ & 0.15 & $-0.22 ; 0.52$ \\
\hline \multicolumn{5}{|l|}{ Clinical and functional characteristics } \\
\hline BMI $\left(\mathrm{kg} / \mathrm{m}^{2}\right)$ & -0.92 & $-2.22 ; 0.38$ & -0.85 & $-2.09 ; 0.39$ \\
\hline Anxiety (score) & -0.22 & $-0.88 ; 0.44$ & -0.01 & $-0.72 ; 0.69$ \\
\hline Depression (score) & -0.18 & $-0.72 ; 0.35$ & -0.09 & $-0.58 ; 0.40$ \\
\hline Worsening of symptoms in the morning (ref no worsening) & 10.7 & $-14.8 ; 36.1$ & 10.2 & $-13.3 ; 33.7$ \\
\hline FEV1 (\% predicted) & $9 \times$ & $0.11 ; 0.74$ & 0.40 & $0.09 ; 0.71$ \\
\hline FVC (\% predicted) & 20 & $0.05 ; 0.58$ & 0.34 & $0.06 ; 0.61$ \\
\hline Pulmonary symptoms (ref no symptoms) & 0.39 & $-9.55 ; 10.3$ & 0.79 & $-9.05 ; 10.6$ \\
\hline Physician-diagnosed COPD (ref newly diagnosed COPD) & -16.1 & $-23.8 ;-8.35$ & -15.1 & $-22.3 ;-7.99$ \\
\hline
\end{tabular}

Results were based on analyses weighted towards the BMI distribution of the general population ( $\mathrm{n}=323$ ); *adjusted for age and sex; BMI, body mass index; CI, confidence interval; COPD, chronic obstructive pulmonary disease; $\mathrm{FEV}_{1}$, forced expiratory volume in 1 second; FVC, forced vital capacity; GOLD, global initiative for chronic obstructive lung disease; MET, metabolic equivalent task;

Table 4. Associated characteristics of physical activity in patients with COPD without comorbid cardiovascular disease or diabetes.

\begin{tabular}{|c|c|c|c|c|}
\hline Characteristics & \multicolumn{2}{|c|}{$\begin{array}{l}\text { Jnadjusted leisure time physical activity } \\
\text { (MET-h/week) }\end{array}$} & \multicolumn{2}{|c|}{$\begin{array}{l}\text { Adjusted* leisure time physical activity } \\
\text { (MET-h/week) }\end{array}$} \\
\hline \multicolumn{5}{|l|}{ Sociodemographic and lifestyle characteristics } \\
\hline Education level (ref low) & -4.17 & $-14.2 ; 5.82$ & -5.58 & $-16.2 ; 5.03$ \\
\hline Working status (ref not working) & -9.34 & $-20.0 ; 1.34$ & -7.18 & $-22.1 ; 7.76$ \\
\hline Smoking status (ref former) & -3.60 & $-14.3 ; 7.15$ & -2.65 & $-13.8 ; 8.49$ \\
\hline Alcohol intake $(\mathrm{g} / \mathrm{d})$ & 0.21 & $-0.23 ; 0.65$ & 0.19 & $-0.23 ; 0.60$ \\
\hline \multicolumn{5}{|l|}{ Clinical and functional characteristics } \\
\hline $\operatorname{BMI}\left(\mathrm{kg} / \mathrm{m}^{2}\right)$ & -0.96 & $-2.54 ; 0.62$ & -0.79 & $-2.30 ; 0.73$ \\
\hline Anxiety (score) & -0.18 & $-0.94 ; 0.59$ & -0.05 & $-0.81 ; 0.80$ \\
\hline Depression (score) & -0.05 & $-0.63 ; 0.52$ & -0.03 & $-0.54 ; 0.53$ \\
\hline Worsening of symptoms in the morning (ref no worsening) & 5.01 & $-20.7 ; 30.7$ & 5.3 & $-18.9 ; 29.6$ \\
\hline FEV1 (\% predicted) & 0.43 & $0.08 ; 0.78$ & 0.41 & $0.07 ; 0.75$ \\
\hline FVC (\% predicted) & 0.31 & $0.02 ; 0.60$ & 0.32 & $0.02 ; 0.62$ \\
\hline Pulmonary symptoms (ref no symptoms) & -2.80 & $-13.4 ; 7.78$ & -1.73 & $-12.9 ; 9.44$ \\
\hline Physician-diagnosed COPD (ref newly diagnosed COPD) & -14.7 & $-22.9 ;-6.50$ & -14.4 & $-22.4 ;-6.38$ \\
\hline
\end{tabular}

Results were based on analyses weighted towards the BMI distribution of the general population ( $\mathrm{n}=259)$; *adjusted for age and sex; BMI, body mass index; CI, confidence interval; COPD, Chronic obstructive pulmonary disease; $\mathrm{FEV}_{1}$, forced expiratory volume in 1 second; $\mathrm{FVC}$, forced vital capacity; GOLD, global initiative for chronic obstructive lung disease; MET, metabolic equivalent task. 


\section{Limitations}

A limitation of this study is that patients might have been included with an obstructive pulmonary function but another diagnosis than COPD (for example asthma, acute and chronic bronchitis, bronchiectasis, cystic fibrosis, and bronchiolitis) [37]. However, patients with an ICPC code R96, never smokers and those with a high FeNO (more likely to be asthma) were excluded. Including asthmatics might have resulted in an overestimation of physical activity since patients with asthma are as physically active as non-asthmatics [38]. Another limitation that is inherent to the population-based design of the study, is the lack of information about COPD symptoms and (hospitalization due to) COPD exacerbation. According to the latest GOLD COPD guidelines, disease severity should be based on lung function, symptoms measured with COPD specific questionnaires and exacerbation history [23]. In the present study, COPD severity was solely based on lung function. This could have resulted in the inclusion of patients with mild or moderate airflow obstruction, but a high burden of disease that result in lower physical activity levels.

In the present study, physical activity may be influenced by suboptimal treatment. Previous placebo-controlled trials have shown positive effects of a LABA $[39,40]$ or a LAMA/LABA combination on physical activity [41]. We hypothesised that some patients who are treated with pulmonary medication were less physically active because they have more severe COPD or experience more severe symptoms, also in patients who are not yet rec- ognized as COPD. We cannot test this hypothesis because of the cross-sectional design of the study, but the ERS statement of physical activity propose different treatment strategies to improve physical activity, like behaviour changes feedback and counselling [3]. Furthermore, in the present study, there was no data available regarding physical activity status before medication use.

The use of ICPC codes to identify patients with COPD can be seen as a limitation because it can lead to an underestimation or overestimation of patients. In this study, there seems to be an underestimation since only 77 of 6,671 participants $(1.1 \%)$ had an ICPC R95. In this study, patients without an ICPC R95 but who are likely to have COPD were included as well. This resulted in the inclusion of 323 patients; COPD incidence of $4.8 \%$ which is representative of a general population. Furthermore, 6 to $17 \%$ of patients with newly diagnosed COPD were prescribed pulmonary medication that suggested the patients were treated as having a pulmonary disease. The difference in $\mathrm{FEV}_{1}$ between physician and newly diagnosed COPD is large, which may drive the differences in other findings. Another limitation of this study is the use of the SQUASH questionnaire to examine physical activity. This activity questionnaire only assessed physical activity in the last four weeks. Furthermore, it has not been validated in COPD. However, this questionnaire has been used in a previous study that included COPD patients [42]. A disadvantage of the use of activity questionnaires is that many patients overestimate their physical activity [43]. Perception of the difficulty of physical activity plays a role in this questionnaire. An activity takes physiological more effort for patients with more airflow limitation. Consequently, the number of

Table 5. Characteristics of patients with physician-diagnosed COPD (GOLD 0-2) and newly diagnosed COPD (GOLD 1-2).

\begin{tabular}{|c|c|c|c|c|c|c|}
\hline Characteristics & $\begin{array}{l}\text { Physician-diagnosed } \\
\text { COPD GOLD } 0 \\
(5.6 \%)\end{array}$ & $\begin{array}{l}\text { Physician-diagnosed } \\
\text { COPD GOLD } 1 \\
(7.3 \%) \\
(55.4 \%)\end{array}$ & $\begin{array}{c}\text { Physician-diagnosed } \\
\text { COPD GOLD } 2 \\
(6.7 \%) \\
(25.0 \%)\end{array}$ & $\begin{array}{c}\text { Newly } \\
\text { diagnosed } \\
\text { COPD GOLD } 1\end{array}$ & $\begin{array}{c}\text { Newly } \\
\text { diagnosed } \\
\text { COPD GOLD } 2\end{array}$ & $\begin{array}{l}\text { Difference } \\
\text { (p-value) }\end{array}$ \\
\hline
\end{tabular}

Sociodemographic and lifestyle characteristics

\begin{tabular}{|c|c|c|c|c|c|c|}
\hline Age (years), median [IQR] & $55[53-59]$ & $62[59-65]$ & $57[48-63]$ & $60[55-64]$ & $59[53-62]$ & 0.369 \\
\hline Sex (\% female) & 75 & 64 & 53 & 34 & 52 & 0.908 \\
\hline Education level (\% high) & 19 & 24 & 24 & 32 & 47 & 0.051 \\
\hline Working status (\% working) & 65 & 60 & 54 & 52 & 57 & 0.453 \\
\hline Smoking status (\% current) & 64 & 31 & 50 & 46 & 61 & 0.256 \\
\hline Alcohol intake $(\mathrm{g} / \mathrm{d})$, median [IQR] & $8[0-21]$ & $21[4-38]$ & $18[0-26]$ & 19 [6-34] & 21 [12-35] & 0.125 \\
\hline \multicolumn{7}{|c|}{ Clinical and functional characteristics } \\
\hline BMI $\left(\mathrm{kg} / \mathrm{m}^{2}\right)$, mean (SD) & $29(6)$ & $25(5)$ & $29(4)$ & $27(4)$ & $27(5)$ & 0.962 \\
\hline Anxiety (score), median [IQR] & $4[2-12]$ & $2[0-5]$ & $5[1-8]$ & $3[1-7]$ & $3[1-6]$ & 0.259 \\
\hline Depression (score), median [IQR] & $6[6-19]$ & $7[6-9]$ & $11[6-23]$ & $8[5-14]$ & $9[6-13]$ & 0.476 \\
\hline FEV1 (L), mean (SD) & $2(1) a, d$ & $3(1) \mathrm{a}$ & $2(0.4) b$ & $3(1) \mathrm{c}$ & $2(0.4) d$ & $<0.001$ \\
\hline FEV1 (\% predicted), mean (SD) & $90(13)$ a & $92(7.8) \mathrm{a}, \mathrm{c}$ & $64(8) b$ & $97(11) \mathrm{c}$ & $73(7) d$ & $<0.001$ \\
\hline FVC (L), mean (SD) & $3(1) \mathrm{a}$ & $4(1) b$ & $4(1) c$ & 5 (1)b & $4(1) c$ & 0.018 \\
\hline FVC (\% predicted), mean (SD) & $98(13) \mathrm{a}$ & $121(13) b$ & $101(12) a$ & $118(14) b$ & 97 (11)a & $<0.001$ \\
\hline FEV1/FVC (ratio), mean (SD) & $76(4) \mathrm{a}$ & $63(4) \mathrm{b}$ & $53(8) \mathrm{c}$ & $66(4) \mathrm{d}$ & $61(6) \mathrm{b}$ & $<0.001$ \\
\hline Respiratory symptoms (\% yes) & 58 & 54 & 82 & 50 & 71 & 0.054 \\
\hline Morning symptoms (\% yes) & 8 & 7 & 8 & 17 & 20 & 0.330 \\
\hline Physical activity in leisure time & $26[23-32]$ & 14 [11-32] & $12[6-35]$ & $35[22-59]$ & $29[16-36]$ & 0.336 \\
\hline
\end{tabular}

(MET hours per week),

median $[\mathrm{IQR}]$

BMI, body mass index; COPD, chronic obstructive pulmonary disease; $\mathrm{FEV}_{1}$, forced expiratory volume in 1 second; FVC, forced vital capacity; GOLD, global initiative for chronic obstructive lung disease; ${ }^{\text {a-d }}$ subset of sample categories that do not differ significantly from each other at the 0.05 level (for variables that differ significantly at the group level). 
Table 6. Associated characteristics of physical activity in patients with physician-diagnosed COPD (GOLD 0-2) and newly diagnosed COPD (GOLD 1-2).

\begin{tabular}{|c|c|c|c|c|c|c|c|}
\hline \multirow[t]{2}{*}{ Characteristics } & \multicolumn{2}{|c|}{$\begin{array}{l}\text { Physician-diagnosed } \\
\text { Adjusted* leisure } \\
\text { time physical activity } \\
\text { (MET-h/week) }\end{array}$} & \multicolumn{2}{|c|}{$\begin{array}{l}\text { Newly diagnosed } \\
\text { Adjusted* leisure } \\
\text { time physical activity } \\
\text { (MET-h/week) }\end{array}$} & \multirow[b]{2}{*}{$\begin{array}{c}\text { P value } \\
\text { *(heterogeneity) }\end{array}$} & \multicolumn{2}{|c|}{$\begin{array}{c}\text { All patients }(\mathrm{n}=323) \\
\text { Adjusted } \\
\text { Pooled estimate }^{\#}\end{array}$} \\
\hline & $\begin{array}{l}\text { Regression } \\
\text { coefficient }\end{array}$ & $95 \% \mathrm{CI}$ & $\begin{array}{l}\text { Regression } \\
\text { coefficient }\end{array}$ & $95 \% \mathrm{CI}$ & & $\begin{array}{l}\text { Regression } \\
\text { coefficient }\end{array}$ & $95 \% \mathrm{CI}$ \\
\hline \multicolumn{8}{|c|}{ Sociodemographic and lifestyle characteristics } \\
\hline Education level (ref low) & 4.5 & $-6.4 ; 15.4$ & -10.7 & $-21.6 ; 0.24$ & 0.088 & - & - \\
\hline Working status (ref not working) & -10.1 & $-18.6 ;-1.5$ & -5.7 & $-23.5 ; 12.2$ & 0.735 & -6.7 & $-20.5 ; 7.0$ \\
\hline Smoking status (ref former) & -0.1 & $-9.7 ; 9.5$ & -3.6 & $-15.5 ; 8.3$ & 0.462 & -2.6 & $-12.8 ; 7.7$ \\
\hline Alcohol intake $(\mathrm{g} / \mathrm{d})$ & 0.0 & $-0.2 ; 0.2$ & 0.2 & $-0.3 ; 0.6$ & 0.467 & 0.1 & $-0.2 ; 0.5$ \\
\hline \multicolumn{8}{|c|}{ Clinical and functional characteristics } \\
\hline BMI $\left(\mathrm{kg} / \mathrm{m}^{2}\right)$ & 0.4 & $-0.3 ; 1.1$ & -1.1 & $-2.6 ; 0.5$ & 0.098 & - & - \\
\hline Anxiety (score) & 0.9 & $0.3 ; 1.6$ & -0.3 & $-1.1 ; 0.6$ & 0.016 & - & - \\
\hline Depression (score) & 0.4 & $-0.0 ; 0.9$ & -0.3 & $-0.9 ; 0.4$ & 0.097 & - & - \\
\hline $\begin{array}{l}\text { Worsening of symptoms in the morning } \\
\text { (ref no worsening) }\end{array}$ & -6.5 & $-18.9 ; 5.9$ & 10.4 & $-15.0 ; 35.9$ & 0.263 & 8.9 & $-14.5 ; 32.3$ \\
\hline FEV1 (L) & -2.0 & $-10.5 ; 6.5$ & 15.9 & $3.8 ; 28.0$ & 0.046 & - & - \\
\hline FEV1 (\% predicted) & -0.0 & $-0.3 ; 0.3$ & 0.4 & $0.1 ; 0.8$ & 0.056 & - & - \\
\hline FVC (L) & -4.6 & $-10.9 ; 1.7$ & 11.0 & $3.6 ; 18.5$ & 0.018 & - & - \\
\hline FVC (\% predicted) & -0.2 & $-0.5 ; 0.1$ & 0.4 & $0.1 ; 0.7$ & 0.002 & - & - \\
\hline Respiratory symptoms (ref no) & 3.6 & $-6.4 ; 13.6$ & 1.2 & $-10.1 ; 12.6$ & 0.673 & 1.8 & $-7.9 ; 11.4$ \\
\hline
\end{tabular}

MET hours per week can be overestimated in patients with more airflow limitation, resulting in fewer differences in physical activity between different GOLD stages. Another limitation is the absence of a reference group and the limited sample size, which resulted in large confidence intervals for some characteristics. There are several limitations related to the absence of data about the quality of sleep, habits (other than smoking and alcohol intake), motivation to maintain a high level of physical activity, which all might limit physical activity.

\section{Conclusions}

The present study showed that lung function was associated with physical activity in COPD patients with mild or moderate airflow obstruction. Furthermore, physical activity was associated with anxiety level only for physician-diagnosed patients. This study suggest that physicians can improve the physical activity level of their COPD patients with mild or moderate airflow obstruction by tailoring physical activity plans according to lung function and anxiety levels.

\section{References}

1. Brawner CA, Churilla JR, Keteyian SJ. Prevalence of Physical activity is lower among individuals with chronic disease. Med Sci Sports Exerc 2016;48:1062-7.
2. Garcia-Aymerich J, Lange P, Benet M, et al. Regular physical activity reduces hospital admission and mortality in chronic obstructive pulmonary disease: a population based cohort study. Thorax 2006;61:772-8.

3. Watz H, Pitta F, Rochester CL, et al. An official European Respiratory Society statement on physical activity in COPD. Eur Respir J 2014;44:1521-37.

4. ZuWallack R, Esteban C. Understanding the impact of physical activity in COPD outcomes: moving forward. Eur Respir J 2014;44:1107-9.

5. Watz H, Waschki B, Meyer T, et al. Physical activity in patients with COPD. Eur Respir J 2009;33:262-72.

6. Van Remoortel H, Hornikx M, Demeyer H, et al. Daily physical activity in subjects with newly diagnosed COPD. Thorax 2013;68:962-3.

7. Fastenau A, van Schayck OC, Gosselink R, et al. Discrepancy between functional exercise capacity and daily physical activity: a cross-sectional study in patients with mild to moderate COPD. Prim Care Respir J 2013;22:425-30.

8. Troosters T, Sciurba F, Battaglia S, et al. Physical inactivity in patients with COPD, a controlled multi-center pilot-study. Respir Med 2010;104:1005-11.

9. Mapel DW, Dalal AA, Blanchette CM, et al. Severity of COPD at initial spirometry-confirmed diagnosis: data from medical charts and administrative claims. Int J Chron Obstruct Pulmon Dis 2011;6:573-81.

10. Gimeno-Santos E, Frei A, Steurer-Stey C, et al. Determinants and outcomes of physical activity in patients with COPD: a systematic review. Thorax 2014;69:731-9.

11. Watz H, Waschki B, Boehme C, et al. Extrapulmonary effects 
of chronic obstructive pulmonary disease on physical activity: a cross-sectional study. Am J Respir Crit Care Med 2008; 177:743-51.

12. Hartman JE, Boezen HM, de Greef MH, et al. Physical and psychosocial factors associated with physical activity in patients with chronic obstructive pulmonary disease. Arch Phys Med Rehabil 2013;94:2396-402.

13. Moy ML, Matthess K, Stolzmann K, et al. Free-living physical activity in COPD: assessment with accelerometer and activity checklist. J Rehabil Res Dev 2009;46:277-86.

14. Watz H, Waschki B, Kirsten A, et al. The metabolic syndrome in patients with chronic bronchitis and COPD: frequency and associated consequences for systemic inflammation and physical inactivity. Chest 2009;136:1039-46.

15. Garcia-Aymerich J, Felez MA, Escarrabill J, et al. Physical activity and its determinants in severe chronic obstructive pulmonary disease. Med Sci Sports Exerc 2004;36:1667-73.

16. Garcia-Rio F, Lores V, Mediano O, et al. Daily physical activity in patients with chronic obstructive pulmonary disease is mainly associated with dynamic hyperinflation. Am J Respir Crit Care Med 2009;180:506-12.

17. Pitta F, Troosters T, Probst VS, et al. Potential consequences for stable chronic obstructive pulmonary disease patients who do not get the recommended minimum daily amount of physical activity. J Bras Pneumol 2006;32:301-8.

18. Monteiro F, Camillo CA, Vitorasso R, et al. Obesity and physical activity in the daily life of patients with COPD. Lung 2012;190:403-10.

19. Nguyen HQ, Fan VS, Herting J, et al. Patients with COPD with higher levels of anxiety are more physically active. Chest 2013;144:145-51.

20. Bourbeau J, Ford G, Zackon H, et al. Impact on patients' health status following early identification of a COPD exacerbation. Eur Respir J 2007;30:907-13.

21. Lahaije AJ, van Helvoort HA, Dekhuijzen PN, et al. Resting and ADL-induced dynamic hyperinflation explain physical inactivity in COPD better than FEV1. Respir Med 2013;107:834-40.

22. de Mutsert R, den Heijer M, Rabelink TJ, et al. The Netherlands Epidemiology of Obesity (NEO) study: study design and data collection. Eur J Epidemiol 2013;28:513-23.

23. COPD standards of the Dutch College of General Practitioners [Internet]. Nederlands Huisartsengenootschap (NHG). 2021. Accessed: 2021 Jun 14. Available from: https://richtlijnen. nhg.org/standaarden/copd

24. Global Initiative for Chronic Obstructive Lung Disease [Internet]. Global Strategy for the Diagnosis, Management and prevention of Chronic Obstructive Pulmonary Disease 2021 Report 2020 Accessed: 2021 Jun 14]. Available from: http://www.goldcopd.org/

25. Wendel-Vos GC, Schuit AJ, Saris WH, et al. Reproducibility and relative validity of the short questionnaire to assess healthenhancing physical activity. J Clin Epidemiol 2003;56:1163-9.

26. Beck AT, Epstein N, Brown G, et al. An inventory for measuring clinical anxiety: psychometric properties. J Consult Clin Psychol 1988;56:893-7.

27. Rush AJ, Gullion CM, Basco MR, et al. The inventory of depressive symptomatology (IDS): psychometric properties. Psychol Med 1996;26:477-86.

28. Miller MR, Hankinson J, Brusasco V, et al. Standardisation of spirometry. Eur Respir J. 2005;26:319-38.

29. Koeneman MA, Verheijden MW, Chinapaw MJ, et al. Determinants of physical activity and exercise in healthy older adults: a systematic review. Int J Behav Nutr Phys Act 2011;8:142.

30. Durstine JL, Gordon B, Wang Z, Luo X. Chronic disease and the link to physical activity. J Sport Health Sci 2013;2:3-11.

31. Korn EL, Graubard BI. Epidemiologic studies utilizing surveys: accounting for the sampling design. Am J Public Health 1991;81:1166-73.

32. Garcia-Aymerich J, Serra I, Gomez FP, et al. Physical activity and clinical and functional status in COPD. Chest 2009;136:62-70.

33. Katajisto M, Koskela J, Lindqvist A, et al. Physical activity in COPD patients decreases short-acting bronchodilator use and the number of exacerbations. Respir Med 2015;109:1320-5.

34. Cindy Ng LW, Mackney J, Jenkins S, et al. Does exercise training change physical activity in people with COPD? A systematic review and meta-analysis. Chron Respir Dis 2012;9:17-26.

35. van Helvoort HA, Willems LM, Dekhuijzen PR, et al. Respiratory constraints during activities in daily life and the impact on health status in patients with early-stage COPD: a cross-sectional study. NPJ Prim Care Respir Med 2016;26: 16054.

36. Ofir D, Laveneziana P, Webb KA, et al. Mechanisms of dyspnea during cycle exercise in symptomatic patients with GOLD stage I chronic obstructive pulmonary disease. Am J Respir Crit Care Med 2008;177:622-9.

37. MedScape [Internet]. Pulmonary function testing; 2018. Available from: https://emedicine.medscape.com/article/ 303239-overview

38. Jerning C, Martinander E, Bjerg A, et al. Asthma and physical activity - a population based study results from the Swedish GA(2)LEN survey. Respir Med 2013;107:1651-8.

39. Watz H, Krippner F, Kirsten A, et al. Indacaterol improves lung hyperinflation and physical activity in patients with moderate chronic obstructive pulmonary disease - a randomized, multicenter, double-blind, placebo-controlled study. BMC Pulm Med 2014;14:158.

40. Hataji O, Naito M, Ito $\mathrm{K}$, et al. Indacaterol improves daily physical activity in patients with chronic obstructive pulmonary disease. Int J Chron Obstruct Pulmon Dis 2013;8:1-5.

41. Watz H, Mailander C, Baier $M$, et al. Effects of indacaterol/glycopyrronium (QVA149) on lung hyperinflation and physical activity in patients with moderate to severe COPD: a randomised, placebo-controlled, crossover study (The MOVE Study). BMC Pulm Med 2016;16:95.

42. Bossenbroek L, ten Hacken NH, van der Bij W, et al. Crosssectional assessment of daily physical activity in chronic obstructive pulmonary disease lung transplant patients. J Heart Lung Transplant 2009;28:149-55.

43. Thyregod M, Bodtger U. Coherence between self-reported and objectively measured physical activity in patients with chronic obstructive lung disease: a systematic review. Int J Chron Obstruct Pulmon Dis 2016;11:2931-8. 